\title{
Physical occupational exposures during working life and quality of life after labour market exit: results from the GAZEL study
}

This is a pre-copyedited, author-produced PDF of an article accepted for publication in Aging \& Mental Health following peer review. The definitive publisher-authenticated version is available online at: http://dx.doi.org/10.1080/13607863.2013.781120 or upon emailing the corresponding author.

Platts, L. G., Netuveli, G., Webb, E., Zins, M., Goldberg, M., Blane, D., \& Wahrendorf, M. (2013). Physical occupational exposures during working life and quality of life after labour market exit: results from the GAZEL study. Aging \& Mental Health, 17(6), 697-706.

Loretta G. Platts $^{\mathrm{a}, \mathrm{b}_{*}}$, Gopalakrishnan Netuveli ${ }^{\mathrm{b}, \mathrm{c}}$, Elizabeth Webb ${ }^{\mathrm{b}, \mathrm{d}}$, Marie Zins ${ }^{\mathrm{e}, \mathrm{f}}$, Marcel Goldberg ${ }^{\mathrm{e}, \mathrm{f}}$, David Blane $\mathrm{e}^{\mathrm{b}, \mathrm{d}}$ \& Morten Wahrendorf ${ }^{\mathrm{b}, \mathrm{d}}$

${ }^{a}$ Department of Primary Care and Public Health, Imperial College London, London, UK

${ }^{\mathrm{b}}$ ESRC International Centre for Lifecourse Studies in Society and Health (ICLS), London, UK

${ }^{\mathrm{c}}$ Institute for Health and Human Development, University of East London, London, UK

${ }^{\mathrm{d}}$ Department of Epidemiology and Public Health, University College London, London, UK

${ }^{\mathrm{e}}$ Population-based Cohorts Platform, INSERM Unit 1018, Villejuif, France

${ }^{\mathrm{f}}$ Versailles Saint Quentin University, UMRS 1018, Villejuif, France

* Corresponding author. Department of Primary Care and Public Health, Reynolds Building, Imperial College London, St Dunstans Road, W6 8RP, UK; loretta.platts@kcl.ac.uk 


\section{Physical occupational exposures during working life and quality of life after labour market exit: results from the GAZEL study}

Objective: To investigate variations in quality of life at older ages we take a life course perspective to analyse long-term effects of physical working conditions upon quality of life after retirement. In doing so, we study to what extent these associations are explained by individuals' health at older ages.

Method: We use administrative data and self-administered questionnaire responses from the French GAZEL cohort. Quality of life was assessed with CASP-19 in 2009 and related to three types of physical working conditions during previous working life: (1) ergonomic strain, (2) physical danger and (3) exposures to chemicals. Health was assessed in 2007 with the SF-36 Health Survey. Multiple regressions were calculated in retired men only, controlling for important confounders including social position.

Results: In contrast to men, few women were exposed to strenuous and dangerous working conditions in this cohort and were not included in subsequent analyses. Negative effects on retired men's quality of life were found for the physical occupational exposures of ergonomic strain and physical danger, but not for chemical exposures. Effects were attenuated after the introduction of physical and mental health to the models, indicating an indirect effect of physical working conditions upon quality of life via health.

Conclusion: Adverse physical working conditions have long-term consequences for health and quality of life at older ages. Improvements to physical working conditions may improve individuals' quality of life over the long term.

Keywords: quality of life, life course, physical work environment, health, CASP-19. 


\section{Introduction}

The period following labour market exit has been associated with an improvement in well-being as individuals are freed from the demands of working life (Westerlund et al., 2010). However, while a period of personal flourishing which can accompany retirement has been described as the Third Age (Laslett, 1991), retirement can also bring risks of social marginalisation and impoverishment (Townsend, 1981). It is possible that exposures to hazards at earlier stages of the life course, such as social, financial and health hazards during working life, may increase individuals' chances of experiencing dependency rather than agency in later life. While the importance of life course circumstances for health in later life has been demonstrated (for reviews see: Blane, Netuveli, \& Stone, 2007; Kuh \& Shlomo, 2004), only a minority of studies have investigated life course influences on quality of life in early old age by explicitly focusing on a measure of quality of life that is not reducible to physical and mental health alone (Hyde, Wiggins, Higgs, \& Blane, 2003; Netuveli, Wiggins, Hildon, Montgomery, \& Blane, 2006).

In this vein, a small but growing literature highlights the importance of early adulthood and mid-life stages in explaining quality of life at older ages. Findings within the life course tradition suggest that previous conditions influence quality of life at older ages indirectly by influencing an individual's current situation; in this way, conditions during working life shape an individual's circumstances in later life as suggested by the pathway model in life course epidemiology (Blane et al., 2007; Blane, 2006). For instance, among older men in the Boyd-Orr cohort, socio-economic disadvantage during working life was associated with worse quality of life via current health and material circumstances, suggesting that earlier disadvantage tended to set men on a path to difficult current circumstances (Blane, Higgs, Hyde, \& Wiggins, 2004). Similarly, in a 
study using the British Household Panel Survey, having had children at younger ages was related to lower quality of life among participants aged over 51 years, a relationship again largely accounted for by current socio-economic and health disadvantages (Read \& Grundy, 2011). A small retrospective survey in the British county of Northamptonshire indicated that aspects of previous employment might influence retirees' quality of life via their effects on the quality of retirement (Lowis, Edwards, \& Singlehurst, 2010). These results indicate the importance of taking a life course perspective in order to understand quality of life at older ages and suggest the importance of earlier working conditions.

Dangerous and strenuous working conditions influence health through a variety of pathways. Safety hazards may influence subsequent health through the long-term impact of injuries while health hazards may result in occupational illness (Levy, Wegman, Baron, \& Sokas, 2011, p. 5). Biomechanical health hazards or ergonomic strain cause long-term and painful musculoskeletal disorders (Descatha et al., 2011; Leclerc, Tubach, Landre, \& Ozguler, 2003; Plouvier, Leclerc, Chastang, Bonenfant, \& Goldberg, 2009; Plouvier, Renahy, Chastang, Bonenfant, \& Leclerc, 2008), while chemical health hazards are likely to influence later health as a result of causing cancer or disabling and often irreversible respiratory illness (Ahasic \& Christiani, 2011, p. 398; Berr et al., 2010; Imbernon et al., 1995; Lundberg, Hemmingsson, \& Hogstedt, 2007, p. 13; Martin, Imbernon, Goldberg, Chevalier, \& Bonenfant, 2000). However, it is not known to what extent the health effects of earlier working conditions affect individuals' chances of enjoying good quality of life following retirement.

In this contribution, we focus on the long-term effects of physical working conditions upon quality of life at older ages, using prospective and retrospective data from the French GAZEL study. In addition, we study how far these conditions exert 
long-term effects on quality of life via their influences on health in later life. In doing so, two well-evidenced associations are considered and studied in a life course framework: first, studies showing that health is an important determinant of quality of life at older ages (Netuveli et al., 2006; Wiggins, Higgs, Hyde, \& Blane, 2004); second, studies in which physical working conditions have been associated with health (for reviews see: Bambra, 2011, chap. 3; Clougherty, Souza, \& Cullen, 2010).

Two further aspects must be considered here. First, we use the CASP-19 scale of quality of life which is specifically designed to measure quality of life in early old age. As older people live longer and healthier lives, it is no longer appropriate to reduce quality of life in older people to their experience of their health. In this way, the CASP-19 measure of quality of life has been developed by drawing on the literature of ageing and the Third Age (Gilleard, 1996; Laslett, 1991), identifying human needs (Doyal \& Gough, 1991) particularly relevant in early old age (control, autonomy, selfrealization, and pleasure (Hyde, Wiggins, Higgs, \& Blane, 2003; see Methods for conceptual details). Consequently, this study with its measure of quality of life relates to the literature of the Third Age. Second, the GAZEL cohort provides detailed information on physical working conditions throughout working life which have been obtained from administrative sources and annually self-administered questionnaires (see measurement for details), enabling a prospective study design to be used. In addition, information on employees' career histories is available for the GAZEL participants, enabling appropriate adjustment for social position which otherwise might confound the effects of physical working conditions upon quality of life (e.g. lower social position in jobs with high physical demands).

Two research questions will be examined: (1) Can variations in quality of life in early old age be predicted from physical occupational exposures during working life? 
We predict that more strenuous and dangerous working conditions over the life course will be associated with lower quality of life following labour market exit. (2) How much is the decline in quality of life related to strenuous and dangerous earlier working conditions due to a decline in health? Since exposure to higher levels of physical occupational exposures has been associated with worse health after retirement and poorer health is a predictor of worse quality of life, we predict that health will mediate the relationships between physical working conditions and subsequent quality of life.

\section{Methods}

\section{Data}

The research questions were explored using the GAZEL occupational cohort of persons employed by the French national gas and electricity company (EDF-GDF). GAZEL participants tended to be hired in their twenties and work for the company until they retired between the ages of 50 and 60 years. Although the GAZEL cohort represents a specific employment sector, the study population was recruited from urban and rural areas throughout France, represents a wide range of occupations and has a socioeconomic structure that compares well to the French population (for a detailed cohort profile, see: Goldberg et al., 2007). Annual questionnaires and administrative records were used to measure physical occupational exposures. At study onset, in 1989, 20625 employees were recruited. By January 2009, 1318 people had died. In our analyses, we were interested in physical occupational exposures and their long-term effects on quality of life after labour market exit. Therefore, we restricted the sample to men and women who were retired in 2009 (excluding a further 985 individuals). We further excluded 81 employees who had worked fewer than 15 years at EDF-GDF by the start of 2009 because they might have received substantial and unrecorded physical 
occupational exposures from employment elsewhere. Finally, individuals with missing data on quality of life, health or retrospective ergonomic strain (7400 people) were excluded to result in a complete case sample of 10841 participants (8498 men and 2343 women). Attrition rates were higher among those who were in poorer health in 1989, reported more ergonomic constraints in 1989 and 1990 and had experienced workplace accidents.

\section{Measures}

\section{Quality of life}

Quality of life was assessed in the self-completion questionnaires with the CASP-19 instrument. It has been specifically designed for early old age, and is widely used in international ageing surveys (Hyde et al., 2003; Netuveli et al., 2006). The CASP-19 measure is intended to be distinct of individual or contextual factors that influence quality of life, such as health or material circumstances, and does not focus on respondents' self-evaluation of quality of life. Rather, a theoretically informed approach based on the satisfaction of certain human needs has been taken (Doyal \& Gough, 1991), emphasizing the more active and reflective dimensions of human nature (Wiggins et al., 2004). Each of the 19 four-point Likert-scaled items in the CASP-19 measure draws from one of four domains: control (C), autonomy (A), self-realization (S), and pleasure (P). A summary measure of the 19 items is used to assess quality of life in this study; the total sum score ranges from 0 to 57, with higher scores indicating a higher overall quality of life. In our sample the value for the internal consistency of the CASP-19 scale (Cronbach's alpha) was 0.88, the mean CASP-19 score was 43.22 and the standard deviation 7.69. Technical details about the CASP-19 scale and results of validation procedures are provided elsewhere (Blane et al., 2004; Hyde et al., 2003; 
Wiggins, Netuveli, Hyde, Higgs, \& Blane, 2008).

\section{Physical working conditions}

In the analyses we distinguished three different types of physical working conditions:

(1) ergonomic strain, (2) physical danger and (3) exposures to chemicals.

(1) Ergonomic strain: Ergonomic strain was measured with two indicators: i) a retrospective ergonomic strain score from the 2007 self-completion questionnaire and ii) a prospective score of ergonomic strain measured in 1989 and 1990.

i) Retrospective ergonomic strain score: In the 2007 questionnaire participants were asked to indicate the start and end years of periods in which they were exposed to any of the following constraints at work: regularly carrying or moving heavy loads, regularly bending forward or twisting the back or trunk, driving a vehicle for two or more hours a day (including commuting to and from work), working on their knees, going up or down more than ten flights of stairs a day, climbing onto ladders or stepladders, working with the hands above the head, carrying loads on the shoulder and using vibrating tools. We created a summed score of career-long exposure by adding the number of different constraints participants were subjected to in each year, and adding together these annual totals to create a summed score of career-long ergonomic exposures. Individuals were grouped into three categories ("no exposure": unexposed; "moderate exposure": exposure level at or below the median for those exposed; "high exposure": exposure level above the median for those exposed).

ii) Ergonomic strain score (1989/1990): In the 1989 and 1990 questionnaires participants were asked whether their current work included any of the five following types of activities: spending a long time on their feet; spending a long time in another tiring posture; long, frequent or rapid journeys in a vehicle; carrying or moving heavy 
loads; or being subjected to shaking or vibrations. Following Melchior et al. (2005), affirmative responses to each item were summed into a score of total ergonomic strain for each year ranging from 0 to 5 . To minimise the influence of temporary activities and thereby reduce measurement error, the scores for 1989 and 1990 were averaged to produce a 1989/1990 score of ergonomic strain.

(2) Physical danger: Physical danger was measured with two indicators: perception of physical hazards in 1989 and 1990 and accident records.

Perception of physical hazards: In the 1989 and 1990 questionnaires, participants indicated whether they thought they were exposed to any of a range of the following seven physical risks in the course of their work: breathing in gas, serious falls, minor falls, being injured by a machine, heat burns, chemical burns, or having a road accident. Affirmative responses to each item were summed to produce total scores of physical hazards in 1989 and 1990. In order to reduce the influence of short-term risks, as well as fluctuations in risk assessments, the scores for 1989 and 1990 were averaged to produce a $0-7$ score indicating exposure to physical hazards for the period $1989 / 1990$.

Accident records: Medically certified sickness absence data from administrative records were used to calculate total numbers of episodes of absences for each participant due to accidents at work (recorded as: accident de travail) between 1978 and 2009. The distribution of accidents was non-normal so a three-group categorical variable was created: a first group containing participants who did not have any accident episodes recorded (no exposure); the remainder were divided into two groups according to whether they had one accident (moderate exposure), or more than one accident (high exposure). 
(3) Exposure to chemicals: To measure exposure to chemicals we used information from the MATEX job-exposure matrix which indicated, for each employee, their estimated annual exposures to harmful chemicals (Imbernon et al., 1996; Imbernon, Goldberg, \& Guénel, 1991). Company occupational physicians regrouped jobs into 403 different occupations and indicated likely exposure levels to each of 30 potential carcinogens. Details about individuals' occupational histories from company records were used to attribute exposures to each employee. Information from the jobexposure matrix is available from 1956 until 1998, when levels of chemical exposure fell to low levels among participants in the GAZEL cohort. We added together the number of different chemicals to which individuals were exposed in each year and then added these annual totals together to create an index of accumulated chemical exposures over the whole career. Next, individuals were regrouped into three categories ("no exposure": unexposed, "moderate exposure": exposure level at or below the median for those exposed, "high exposure": exposure level above the median for those exposed).

\section{Health functioning}

Mental and physical component summary scores from the French standard version of the Short Form 36 Health Survey (SF-36) were used to measure health functioning in 2007 (Leplège, Ecosse, Coste, Pouchot, \& Perneger, 2001; Ware Jr \& Sherbourne, 1992). The SF-36 questionnaire is an internationally validated measure of health functioning composed of 36 questions about physical and mental functioning which are grouped into eight subscales depicting different health domains. The internal consistency of the single domains proved satisfactory in our sample (Cronbach's alphas vary between 0.80 and 0.84 ) and two summary scores were derived, a mental component summary score (SF-36 MCS) and a physical component summary score (SF-36 PCS), both ranging from 0-100 with higher scores indicating better health. The 
psychometric properties of the French SF-36 and the construction of the two scores are fully described elsewhere (Leplège et al., 2001).

\section{Additional variables}

We included a number of socio-demographic variables as controls in the multivariate analyses. Age and age-squared were included because quality of life is known to have a non-linear relationship with age (Zaninotto, Falaschetti, \& Sacker, 2009). To minimize the risk that any observed association between physical working conditions and quality of life was due to respondents' social position, two complementary measures of social position have been used in the multiple analyses: social class and occupational grade (both measured in 1989).

Social class was measured using the European Socio-economic Classification (ESeC) (Rose \& Harrison, 2007). It categorizes individuals according to particular aspects of the work setting and the labour market situation. More specifically, occupations are grouped according to the degree of specificity of human assets they require and of the difficulty managers face in monitoring the quality and quantity of work produced (Rose, Harrison, \& Pevalin, 2009, pp. 10-14). To classify respondents into $\mathrm{ESeC}$, we used the four-digit French national social class classification available in GAZEL and the conversion table developed by Louis-André Vallet and Christel Colin at the French National Institute of Statistics and Economic Studies (Brousse, Monso, \& Wolff, 2007, pp. 87-95). Because all the GAZEL participants were employed, only seven of the existing $10 \mathrm{ESeC}$ classes were available for our study. These are: $\mathrm{ESeC} 1$ (Large employers, higher grade professionals, administrative and managerial occupations); ESeC2 (Lower grade professional, administrative and managerial occupations and higher grade technicians and supervisory occupations); ESeC3 (Intermediate occupations); ESeC6 (Lower supervisory and lower technician 
occupations); ESeC7 (Lower sales, services and clerical occupations); ESeC8 (Lower technical occupations); and ESeC9 (Routine occupations).

The second measure, occupational grade, is an internal company classification. It classifies all occupations on a continuous scale, ranging from 1 to 52 in this panel, with higher values being associated with higher salary and higher status within the company. These complementary measures, social class and occupational grade, have been used as controls because each focuses on different aspects of social position: social class on the nature of employment relationships, and occupational grade on an occupation's salary, position with the company hierarchy and prestige within the organization.

\section{Statistical analysis}

The analyses were carried out in Stata 12.1 (StataCorp, 2011a); men and women were analyzed separately. First, descriptive analyses were used to explore sample characteristics (Table 1Table ). Second, we studied correlations between all variables under study for men only, given the low frequencies of strenuous and dangerous physical working conditions among women (Table 2).

We examined mean quality of life scores for each of the three categorical indicators of occupational exposures (retrospective ergonomic constraints, accumulated accidents and accumulated chemical exposures) in order to illustrate the crude associations between physical working conditions and quality of life in men (Figure 1).

Next, to test our two research questions, we estimated ordinary least squares (OLS) linear regression models to predict quality of life in 2009 for men (Table 3). In Table 3 we present unstandardized regression coefficients together with standard errors and levels of significance, as well as one measure of model fit (coefficient of

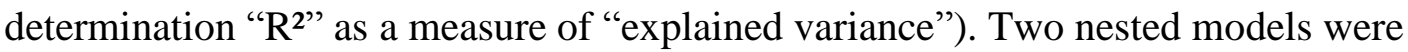


estimated for each of the five occupational exposures. First, the effects of adverse physical working conditions were calculated, adjusted for age and the two measures of occupational position (Model 1). These models allow the effect of each occupational exposure to be tested separately (research question 1). Next, in Model 2, mental and physical health functioning was added to the models. By comparing the coefficients of the models, we examined the degree to which associations between physical working conditions and quality of life were mediated by health (research question 2).

To address a possible bias due to sample attrition and item non-response, multiple imputations were carried out as a test of robustness (Allison, 2002). The imputations were performed in Stata 12.1 using chained equations with augmentation where necessary (StataCorp, 2011b). To create the multiply imputed datasets, in addition to the covariates, variables were included that have previously been shown to predict attrition (Goldberg, Chastang, Zins, Niedhammer, \& Leclerc, 2006) and that predict likely values for missing variables. For each model, 10 imputations were carried out each preceded by 10 iterations. The multiply imputed results are not presented in detail.

\section{Results}

\section{Descriptive findings}

Before examining the main research questions, we will briefly describe the sample as presented in Table 1. In 2009, when quality of life was measured, men's mean age was two years older than women's. Mean employment grade was higher for men than women and men were more likely to hold management and professional positions and supervisory blue-collar roles. In contrast, women tended to occupy white-collar posts; very few women held blue collar roles. Regarding our exposures of interest, men had 
been exposed to more strenuous and dangerous working conditions than women, particularly for exposure to ergonomic strain and harmful chemicals where high levels of exposures were nearly non-existent for women. Male participants had better physical and mental health and reported better quality of life.

\section{Bivariate associations}

Table 2 displays all the correlation coefficients between the main variables. These analyses are restricted to men, because very few women had been exposed to adverse physical working conditions. In summary, the occupational exposures were positively correlated with each other, including the retrospective and prospective indicators of ergonomic strain, which provides some support for the reliability of the self-reported measures. Turning to the associations between social position and physical working conditions, higher grade and higher social class (the highest ESeC classes 1, 2, and 3 are non-manual) are associated with lower levels of exposures in men. Physical working conditions were weakly negatively correlated with physical and mental health functioning in men. There were positive correlations between physical and mental health functioning and quality of life. All types of physical working conditions were weakly negatively correlated with quality of life at older ages.

Figure 1 displays mean CASP-19 scores and 95\% confidence intervals for the three categorical indicators of working conditions under study (retrospective ergonomic constraints, accumulated accidents and accumulated chemical exposure). In each case, the most exposed men reported lowest levels of quality of life, while quality of life was highest among those with no exposure. The differences are statistically significant at $\mathrm{p}<0.001$ (ANOVA). For the accumulated accidents measure of physical danger the difference in mean scores between the no exposure and high exposure groups is almost two CASP-19 points. 
Do these associations persist after adjustment for important confounders? And how far does physical and mental health mediate these associations? These questions were answered in the two sets of models presented in Table 3, in which Model 1 controls for important confounders and Model 2 additionally includes health.

\section{Multivariate findings}

The findings of the multivariate analyses support the relationship between CASP-19 and occupational exposures which was suggested by the bivariate analyses. With the exception of chemical exposures, the associations between the physical occupational exposures and quality of life are statistically significant after controlling for social position in Model 1 (Table 3). In Model 2, after inclusion of physical and mental health measures, model fit improves and the associations between each physical occupational exposure and quality of life attenuate or reverse. This suggests that the associations between physical occupational exposures and quality of life are accounted for once physical and mental health measures are included in the model.

The results of additional analyses using the multiply imputed data sets described in the methods section did not differ substantially from those displayed in Table 3 (results not shown). The magnitude and statistical significance of coefficients were similar for each measure of occupational exposure, as well as the findings suggesting a mediating role for health.

\section{Discussion}

This paper uses data from the GAZEL cohort to study the long-term effects of physical working conditions on quality of life after labour market exit and finds that exposure to negative physical working conditions across the working life course is associated with worse quality of life in early old age. We study to what extent health in later life 
accounts for the observed association, since working conditions are known to influence health in later life (Bodin et al., 2012; Descatha et al., 2011; Niedhammer, Chastang, David, \& Kelleher, 2008), and health in turn is associated with quality of life (Farquhar, 1995; Webb, Blane, McMunn, \& Netuveli, 2011; Zaninotto et al., 2009). To assess physical working conditions, we used administrative data combined with information from self-completion questionnaires and divided the exposure into three types: (1) ergonomic strain, (2) physical danger and (3) exposures to harmful chemicals. The CASP-19 questionnaire was used to indicate quality of life. To measure health in early old age we used mental and physical component scores from the SF-36 questionnaire.

The main findings can be summarized as follows: First, few women were exposed to adverse working conditions and those who were generally received low levels of exposure. In contrast, levels of physical occupational exposures were higher for men and consistent associations with quality of life were found for both measures of ergonomic strain and of physical danger, but not for chemical exposures. The associations of ergonomic strain and physical danger with quality of life remained statistically significant after adjustments for possible confounders including employment grade, social class and age of the study participants. It is possible that negative results for chemical exposures might be due to loss to follow-up due to death (Martin et al., 2000). Previous work in the Gazel cohort has shown long-term effects of solvents on cognition at high levels of exposure (Berr et al., 2010; Sabbath et al., 2012); perhaps a lack of association with quality of life in the current study was a result of using a nonspecific measure of lifetime chemical exposure. In summary, these results underline the importance of previous physical working conditions for quality of life in early old age. 
Our second main finding draws attention to the mediating effect of health functioning in later life upon the relationship between physical working conditions and quality of life. For men, the associations of exposure to physical danger and ergonomic strain in the workplace with quality of life were attenuated after introduction of measures of physical and mental health functioning into the models. Corresponding to previous studies finding adverse effects of physical working conditions on later health (e.g., National Institute for Occupational Safety and Health 1997; Punnett and Wegman 2004), this result suggests that the association between working conditions and quality of life is partially mediated by health.

Additional aspects of working conditions and further mechanisms may help explain the associations with mental health. For instance, poorer mental health functioning in later life could have resulted from poorer physical health or from other characteristics of the working environment such as high levels of work stress (Wahrendorf et al., 2012).

We found negative impacts of physical occupational exposures regardless of whether a measure of ergonomic strain from a two-year period in 1989/1990 or a retrospective measure of career exposures to ergonomic strain was used. This could be because the level of exposure to ergonomic strain in 1989/1990 is a good indicator of career-long ergonomic strain, perhaps because employees tended to have similar sorts of career trajectories.

To our knowledge this is the first prospective study examining long-term influences of physical working conditions upon quality of life in early old age. Our findings add to the existing literature of the determinants of quality of life in older ages, first, by pointing to the importance of previous physical working conditions for later quality of life, and second, by highlighting the possible mediating role of health. These 
results extend earlier findings of long-term effects of conditions in previous life stages on quality of life (Blane et al., 2004) by studying the interrelations between previous working conditions, health in later life and quality of life after labour exit within a life course framework.

\section{Strengths and limitations}

The study design of the GAZEL cohort, in particular its large study sample and low attrition rates, is a particular strength of the study (Zins, Leclerc, \& Goldberg, 2009). Uniquely, the GAZEL cohort provides detailed information on three different types of physical occupational exposures, based on administrative data and on self-reports and covering a long time-frame. Similarly, quality of life and health were measured by the full original versions of two theoretically grounded and internationally established questionnaires (Hyde et al., 2003; Leplège et al., 2001) and two complementary measures of social position were included as important confounders. However, several limitations of this study must be discussed.

First, despite a population that is socially and geographically diverse (Goldberg et al., 2007), conclusions from analyses of the GAZEL cohort data must be drawn carefully, since important segments of the population (e.g. unemployed people and selfemployed workers) are absent. Furthermore, working conditions of the GAZEL cohort are considered to be generally better than those in the French population, given that participants held stable posts in a nationalised company. These might lead the impact of physical working conditions upon quality of life to be underestimated in this study. The influences of dangerous and strenuous working conditions could be greater in a less well protected population.

Second, only one quarter of the respondents in our study were female, and the majority of women employed at GDF/EDF held white-collar posts. Consequently, few 
women were exposed to strenuous and dangerous working conditions and the relationship between physical occupational exposures during working life and quality of life following retirement could therefore not be explored amongst women here.

Third, by restricting the sample to people who had already left the labour market in 2009, some selection bias could have affected our findings, given that poor health might be one reason for labour market exit, and thus respondents in poor health may be overrepresented. However, sensitivity analyses which included men who were still working in 2009 gave similar results.

Fourth, although most data on occupational exposures were obtained from administrative records or from baseline in 1989, sample attrition had occurred by the time quality of life was recorded in 2009 and it may be possible that a systematic nonresponse bias occurred because people with more health problems were more likely to stop participating in the study (Goldberg et al., 2006). Similarly, people in good health may be more likely to give information on their quality of life. However, the robustness of these results has been tested by carrying out multiple imputations in which variables known to predict attrition were included and the findings were replicated.

Lastly, some readers may be concerned that the measures of health (SF-36) and quality of life (CASP-19) used in this analysis overlap, because SF-36 is sometimes used to measure health-related quality of life. We would argue that the measures are conceptually distinct, as CASP-19 explicitly focuses on aspects of quality of life that are not reducible to physical and mental health. Further research could use other health measures to confirm the results.

In this contribution we focussed on associations between physical working conditions and quality of life after labour market exit and the explanation of this association by health. In doing so, other important potential determinants of quality of 
life were not included in the analyses. For instance, our findings clearly indicate that social position is associated with quality of life after labour market exit. Although our multivariate analyses control for social position and independent effect of physical working conditions could be observed in our final model, other factors associated with low social position (e.g. psychosocial work stress, health behaviours) could be investigated in subsequent studies. Similarly, analyses could examine whether the impact of physical occupational exposures varies according to the individual's social position or the timing of the exposure, or whether effects of chemical exposures can be found by differentiating exposures by type of chemicals or duration of exposure.

\section{Conclusion}

In conclusion, this study has shown that long-term exposure to ergonomic strain and physical hazards influence quality of life after labour market exit through their impact upon mental and physical health. After taking account of the effects of social class and occupational grade, findings suggest that physical work exposures during the life course have long-range effects upon subsequent quality of life. Improvements to working conditions to reduce exposure to strenuous and dangerous activities could increase quality of life as well as health over the long term.

\section{Acknowledgements}

The work is funded by the ESRC International Centre for Life Course Studies in Society and Health (Award Number RES-596-28-0001). MW was additionally supported by the German Research Foundation (Project Number: Wa 3065/1-1). The GAZEL Cohort Study was funded by EDF-GDF and INSERM and received grants from the "Cohortes Santé TGIR Program" and from the "Agence nationale de la recherche". Assistance in classifying the GAZEL employees into $\mathrm{ESeC}$ social classes was kindly provided by Dr Eric Harrison at City University (London) and Dr Louis-André Vallet at Crest-Insee (Centre for Research in Economics and Statistics, National Institute of Statistics and Economic Studies, Paris). We would like to thank the staff in 
the équipe Epidémiologie des déterminants professionnels et sociaux de la santé from the INSERM unit 1018, two anonymous reviewers and especially the GAZEL cohort participants.

\section{References}

Ahasic, A. M., \& Christiani, D. C. (2011). Respiratory disorders. In B. S. Levy, D. H. Wegman, S. L. Baron, \& R. K. Sokas (Eds.), Occupational and Environmental Health: Recognizing and Preventing Disease and Injury (pp. 398-427). New York, NY: Oxford University Press.

Allison, P. D. (2002). Missing Data. London: Sage.

Bambra, C. (2011). Work, Worklessness, and the Political Economy of Health. Oxford: Oxford University Press.

Berr, C., Vercambre, M. N., Bonenfant, S., Singh-Manoux, A., Zins, M., \& Goldberg, M. (2010). Occupational exposure to solvents and cognitive performance in the GAZEL cohort: Preliminary results. Dementia and Geriatric Cognitive Disorders, 30(1), 12-19. doi:10.1159/000315498

Blane, D. (2006). The life course, the social gradient, and health. In M. G. Marmot \& R. G. Wilkinson (Eds.), Social Determinants of Health (2nd ed., pp. 54-77). Oxford: Oxford University Press.

Blane, D., Higgs, P. F. D., Hyde, M., \& Wiggins, R. D. (2004). Life course influences on quality of life in early old age. Social Science \& Medicine, 58(11), 21712179. doi:10.1016/j.socscimed.2003.08.028

Blane, D., Netuveli, G., \& Stone, J. (2007). The development of life course epidemiology=L'émergence de l'épidémiologie biographique. Revue d'épidémiologie et de santé publique, 55, 31-38.

Bodin, J., Ha, C., Petit Le Manac’h, A., Sérazin, C., Descatha, A., Leclerc, A., ... Roquelaure, Y. (2012). Risk factors for incidence of rotator cuff syndrome in a 
large working population. Scandinavian Journal of Work, Environment \& Health, 38(5), 436-446. doi:10.5271/sjweh.3285

Brousse, C., Monso, O., \& Wolff, L. (2007). Is prototype ESeC relevant a classification to depict employment relations in France (Direction des Statistiques Démographiques et Sociales No. F0705). Institut national de la statistique et des études économiques. Retrieved from http://www.insee.fr/fr/publications-etservices/docs_doc_travail/f0705.pdf

Clougherty, J. E., Souza, K., \& Cullen, M. R. (2010). Work and its role in shaping the social gradient in health. Annals of the New York Academy of Sciences, 1186, 102-124. doi:10.1111/j.1749-6632.2009.05338.x

Descatha, A., Cyr, D., Imbernon, E., Chastang, J.-F., Plenet, A., Bonenfant, S., ... Leclerc, A. (2011). Long-term effects of biomechanical exposure on severe knee pain in the Gazel cohort. Scandinavian Journal of Work, Environment \& Health, $37(1), 37-44$.

Doyal, L., \& Gough, I. (1991). A Theory of Human Need. Basingstoke, Hampshire: Palgrave Macmillan.

Farquhar, M. (1995). Elderly people's definitions of quality of life. Social Science \& Medicine, 41(10), 1439-1446. doi:10.1016/0277-9536(95)00117-P

Gilleard, C. J. (1996). Consumption and identity in later life: toward a cultural gerontology. Ageing \& Society, 16(04), 489-498. doi:10.1017/S0144686X00003640

Goldberg, M., Chastang, J.-F., Zins, M., Niedhammer, I., \& Leclerc, A. (2006). Health problems were the strongest predictors of attrition during follow-up of the GAZEL cohort. Journal of Clinical Epidemiology, 59(11), 1213-1221. doi:10.1016/j.jclinepi.2006.02.020 
Goldberg, M., Leclerc, A., Bonenfant, S., Chastang, J.-F., Schmaus, A., Kaniewski, N., \& Zins, M. (2007). Cohort profile: the GAZEL Cohort Study. International Journal of Epidemiology, 36(1), 32-39. doi:10.1093/ije/dyl247

Hyde, M., Wiggins, R. D., Higgs, P. F. D., \& Blane, D. (2003). A measure of quality of life in early old age: the theory, development and properties of a needs satisfaction model (CASP-19). Aging \& Mental Health, 7(3), 186-194. doi:10.1080/1360786031000101157

Imbernon, E., Goldberg, M., Bonenfant, S., Chevalier, A., Guénel, P., Vatré, R., \& Dehaye, J. (1995). Occupational respiratory cancer and exposure to asbestos: A case-control study in a cohort of workers in the electricity and gas industry. American Journal of Industrial Medicine, 28(3), 339-352. doi:10.1002/ajim.4700280304

Imbernon, E., Goldberg, M., \& Guénel, P. (1991). MATEX : une matrice emploisexpositions destinée à la surveillance épidémiologique des travailleurs d'une grande entreprise (E.D.F.-G.D.F.) [MATEX: a job-exposure matrix for the epidemiological surveillance of workers in a large company (E.D.F.-G.D.F.)]. Archives des Maladies Professionnelles, 52, 559-66.

Imbernon, E., Goldberg, M., Guénel, P., Chevalier, A., Vatré, R., \& Bonenfant, S. (1996). Validation of asbestos exposure assessment in a job-exposure matrix in the electricity and gas industry in France: the MATEX project. Occupational Hygiene, 3(1-3), 193-198.

Kuh, D., \& Shlomo, Y. B. (2004). A Life Course Approach to Chronic Disease Epidemiology (2nd ed.). Oxford: Oxford University Press.

Laslett, P. (1991). A Fresh Map of Life: The Emergence of the Third Age. Cambridge, MA: Harvard University Press. 
Leclerc, A., Tubach, F., Landre, M. - F., \& Ozguler, A. (2003). Personal and occupational predictors of sciatica in the GAZEL cohort. Occupational Medicine, 53(6), 384 -391. doi:10.1093/occmed/kqg072

Leplège, A., Ecosse, E., Coste, J., Pouchot, J., \& Perneger, T. (2001). Le questionnaire MOS SF-36: Manuel de l'utilisateur et guide d'interprétation des scores [The MOS SF-36 questionnaire: User's manual and guide to interpretation of scores]. Paris: Estem.

Levy, B. S., Wegman, D. H., Baron, S. L., \& Sokas, R. K. (2011). Occupational and environmental health: Twenty-first challenges and opportunities. In B. S. Levy, D. H. Wegman, S. L. Baron, \& R. K. Sokas (Eds.), Occupational and Environmental Health: Recognizing and Preventing Disease and Injury (pp. $3-$ 22). New York, NY: Oxford University Press.

Lowis, M. J., Edwards, A. C., \& Singlehurst, H. M. (2010). The relationship between preretirement occupation and older adults' life satisfaction and self-rated health. The Journal of Psychology: Interdisciplinary and Applied, 145(1), 59-72.

Lundberg, I., Hemmingsson, T., \& Hogstedt, C. (2007). Introductory review and background. In I. Lundberg, T. Hemmingsson, \& C. Hogstedt (Eds.), Work and social inequalities in health in Europe (pp. 11-33). Brussels: Peter Lang.

Martin, J.-C., Imbernon, E., Goldberg, M., Chevalier, A., \& Bonenfant, S. (2000). Occupational risk factors for lung cancer in the French electricity and gas industry: a case-control survey nested in a cohort of active employees. American Journal of Epidemiology, 151(9), 902-912.

Melchior, M., Krieger, N., Kawachi, I., Berkman, L. F., Niedhammer, I., \& Goldberg, M. (2005). Work factors and occupational class disparities in sickness absence: 
findings from the GAZEL cohort study. American Journal of Public Health, 95(7), 1206-1212. doi:10.2105/AJPH.2004.048835

National Institute for Occupational Safety and Health. (1997). Musculoskeletal

Disorders and Workplace Factors: A Critical Review of Epidemiologic Evidence for Work-Related Musculoskeletal Disorders of the Neck, Upper Extremity, and Low Back (No. 97-141). Cincinnati, OH: Centers for Disease Control. Retrieved from http://www.cdc.gov/niosh/docs/97-141/pdfs/97-141.pdf

Netuveli, G., Wiggins, R. D., Hildon, Z., Montgomery, S. M., \& Blane, D. (2006). Quality of life at older ages: evidence from the English longitudinal study of aging (wave 1). Journal of Epidemiology and Community Health, 60(4), 357363. doi:10.1136/jech.2005.040071

Niedhammer, I., Chastang, J.-F., David, S., \& Kelleher, C. (2008). The contribution of occupational factors to social inequalities in health: Findings from the national French SUMER survey. Social Science \& Medicine, 67(11), 1870-1881. doi:10.1016/j.socscimed.2008.09.007

Plouvier, S., Leclerc, A., Chastang, J.-F., Bonenfant, S., \& Goldberg, M. (2009). Socioeconomic position and low-back pain--the role of biomechanical strains and psychosocial work factors in the GAZEL cohort. Scandinavian Journal of Work, Environment \& Health, 35(6), 429-436.

Plouvier, S., Renahy, E., Chastang, J.-F., Bonenfant, S., \& Leclerc, A. (2008). Biomechanical strains and low back disorders: quantifying the effects of the number of years of exposure on various types of pain. Occupational and Environmental Medicine, 65(4), 268-274. doi:10.1136/oem.2007.036095 
Punnett, L., \& Wegman, D. H. (2004). Work-related musculoskeletal disorders: the epidemiologic evidence and the debate. Journal of Electromyography and Kinesiology, 14(1), 13-23. doi:10.1016/j.jelekin.2003.09.015

Read, S., \& Grundy, E. (2011). Fertility history and quality of life in older women and men. Ageing \& Society, 31(01), 125-145. doi:10.1017/S0144686X10000760

Rose, D., \& Harrison, E. (2007). The European socio-economic classification: a new social class schema for comparative European research. European Societies, $9(3), 459-490$.

Rose, D., Harrison, E., \& Pevalin, D. (2009). The European Socio-Economic Classification: A prolegomenon. In D. Rose \& E. Harrison (Eds.), Social Class in Europe: An introduction to the European Socio-economic Classification (pp. 3-38). London: Routledge.

Sabbath, E. L., Glymour, M. M., Berr, C., Singh-Manoux, A., Zins, M., Goldberg, M., \& Berkman, L. F. (2012). Occupational solvent exposure and cognition: Does the association vary by level of education? Neurology, 78(22), 1754-1760. doi:10.1212/WNL.0b013e3182583098

StataCorp. (2011a). Stata Statistical Software: Release 12. College Station, TX: StataCorp LP.

StataCorp. (2011b). mi impute chained. In Multiple Imputation Reference Manual (pp. 135-161). College Station, TX: Stata Press.

Townsend, P. (1981). The structured dependency of the elderly: a creation of social policy in the twentieth century. Ageing \& Society, 1(1), 5-28. doi:10.1017/S0144686X81000020

Wahrendorf, M., Sembajwe, G., Zins, M., Berkman, L. F., Goldberg, M., \& Siegrist, J. (2012). Long-term effects of psychosocial work stress in midlife on health 
functioning after labor market exit - results from the GAZEL study. The Journals of Gerontology Series B: Psychological Sciences and Social Sciences, 67(4), 471-480. doi:10.1093/geronb/gbs045

Ware Jr, J. E., \& Sherbourne, C. D. (1992). The MOS 36-item short-form health survey (SF-36): I. Conceptual framework and item selection. Medical care, 30(6), 473483.

Webb, E., Blane, D., McMunn, A., \& Netuveli, G. (2011). Proximal predictors of change in quality of life at older ages. Journal of Epidemiology and Community Health, 65(6), 542-7. doi:10.1136/jech.2009.101758

Westerlund, H., Vahtera, J., Ferrie, J. E., Singh-Manoux, A., Pentti, J., Melchior, M., ... Kivimäki, M. (2010). Effect of retirement on major chronic conditions and fatigue: The French GAZEL occupational cohort study. British Medical Journal, 341, c6149. doi:10.1136/bmj.c6149

Wiggins, R. D., Higgs, P. F. D., Hyde, M., \& Blane, D. (2004). Quality of life in the third age: key predictors of the CASP-19 measure. Ageing \& Society, 24(5), 693-708.

Wiggins, R. D., Netuveli, G., Hyde, M., Higgs, P. F. D., \& Blane, D. (2008). The evaluation of a self-enumerated scale of quality of life (CASP-19) in the context of research on ageing: a combination of exploratory and confirmatory approaches. Social Indicators Research, 89(1), 61-77. doi:10.1007/s11205-007$9220-5$

Zaninotto, P., Falaschetti, E., \& Sacker, A. (2009). Age trajectories of quality of life among older adults: results from the English Longitudinal Study of Ageing. Quality of Life Research, 18(10), 1301-1309. doi:10.1007/s11136-009-9543-6 
Zins, M., Leclerc, A., \& Goldberg, M. (2009). The French GAZEL Cohort Study: 20 years of epidemiologic research. Advances in Life Course Research, 14(4), 13546. doi:10.1016/j.alcr.2010.02.003 
Table 1: Description of measures and sample $(\mathrm{N}=10841)$

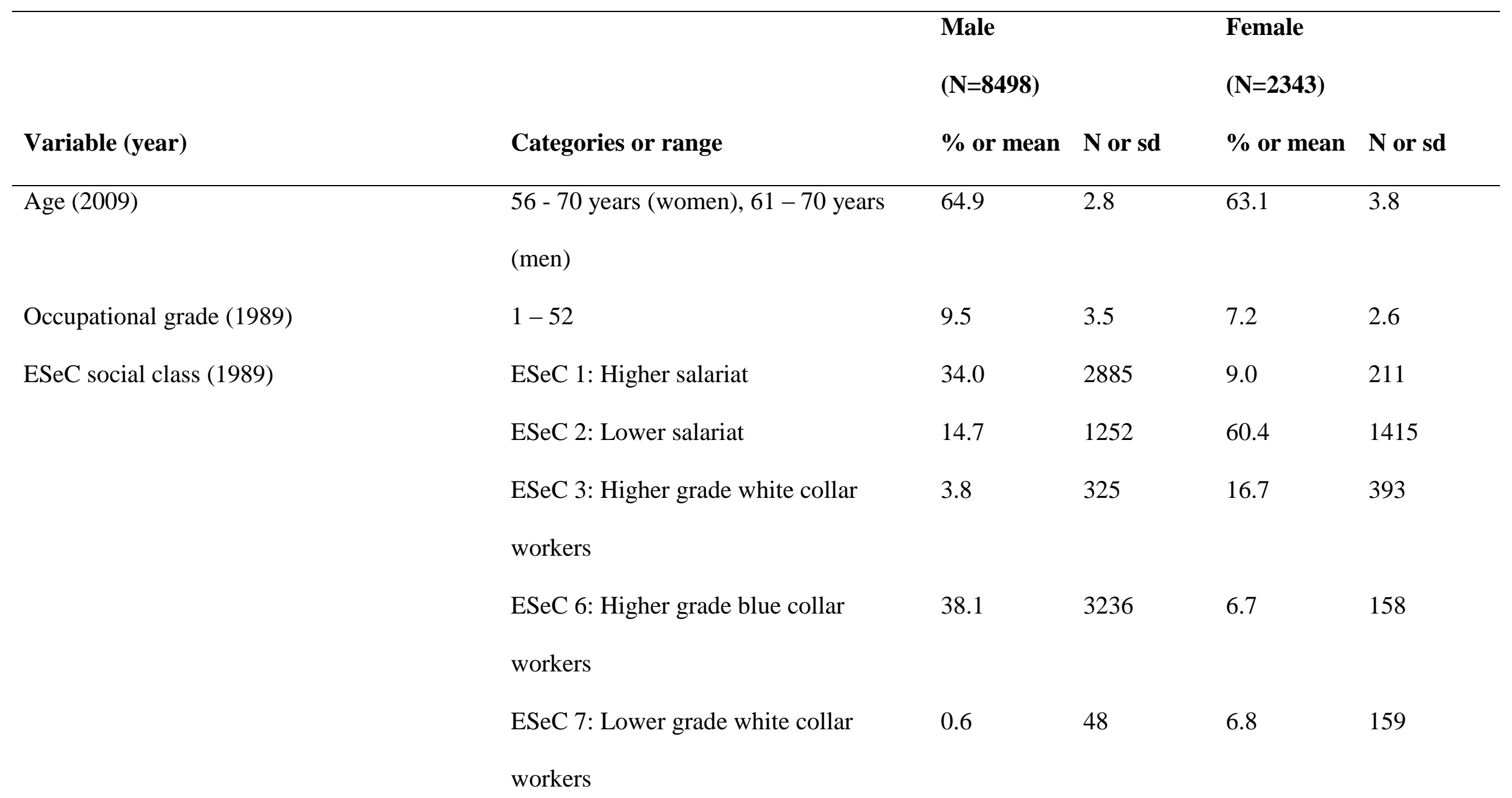


ESeC 8: Skilled workers

ESeC 9: Semi- \& non-skilled workers
8.6

35.0

Retrospective

ergonomic

constraints No exposure

(2007)

\begin{tabular}{ll} 
& \multicolumn{1}{l}{ Moderate exposure } \\
& High exposure \\
Ergonomic strain score $(1989 / 1990)$ & $0-5$ \\
ysical danger & \\
Physical hazards score $(1989 / 1990)$ & $0-7$ \\
Accumulated accidents $(1978-2009)$ & No exposure \\
& Moderate exposure \\
& High exposure
\end{tabular}

Exposure to harmful chemicals

Accumulated chemical exposures (1956- No exposure

\section{Ergonomic strain}

High exposure
30.0

35.0

0.9

1.6

83.2

11.6

5.2

39.4
2978

77.6

.

20.2

2974

1.0

0.3

0.5 0.5 053

77 
1998)

\begin{tabular}{|c|c|c|c|c|c|}
\hline & Moderate exposure & 31.9 & 2709 & 1.0 & 23 \\
\hline & High exposure & 28.8 & 2443 & 0.0 & 1 \\
\hline SF-36 MCS (2007) & $0.3-71.3$ & 49.4 & 8.9 & 45.7 & 10.9 \\
\hline SF-36 PCS (2007) & $13.6-68.9$ & 50.3 & 6.8 & 49.4 & 7.9 \\
\hline CASP-19 score (2009) & $7-57$ & 43.5 & 7.4 & 42.3 & 8.8 \\
\hline
\end{tabular}


Table 2: Intercorrelations between the main variables: all correlation coefficients are significant at $\mathrm{p}<0.05$ apart from the value marked ${ }^{\mathrm{a}}(\mathrm{N}=8498$ men)

\begin{tabular}{|c|c|c|c|c|c|c|c|c|c|c|c|}
\hline & 1. & 2. & 3. & 4. & 5. & 6. & 7. & 8. & 9. & 10. & 11. \\
\hline 1. Age & - & & & & & & & & & & \\
\hline 2. Occupational grade & 0.14 & - & & & & & & & & & \\
\hline 3. ESeC social class & -0.12 & -0.71 & - & & & & & & & & \\
\hline \multicolumn{12}{|l|}{ Ergonomic strain } \\
\hline 4. Accumulated ergonomic strain & -0.05 & -0.37 & 0.42 & - & & & & & & & \\
\hline 5. Ergonomic strain score & -0.08 & -0.34 & 0.40 & 0.36 & - & & & & & & \\
\hline \multicolumn{12}{|l|}{ Physical danger } \\
\hline 6. Physical hazards score & -0.10 & -0.30 & 0.41 & 0.36 & 0.60 & - & & & & & \\
\hline 7. Accumulated accidents & -0.07 & -0.26 & 0.27 & 0.19 & 0.27 & 0.22 & - & & & & \\
\hline \multicolumn{12}{|l|}{ Exposures to harmful chemicals } \\
\hline 8. Accumulated chemical exposures & -0.06 & -0.43 & 0.53 & 0.46 & 0.33 & 0.43 & 0.22 & - & & & \\
\hline 9. SF-36 MCS & -0.03 & 0.06 & -0.02 & -0.04 & -0.05 & -0.03 & -0.05 & $0.00^{\mathrm{a}}$ & - & & \\
\hline 10. SF-36 PCS & -0.10 & 0.08 & -0.06 & -0.12 & -0.09 & -0.06 & -0.09 & -0.07 & 0.04 & - & \\
\hline 11. CASP-19 & -0.07 & 0.12 & -0.09 & -0.06 & -0.08 & -0.06 & -0.08 & -0.05 & 0.51 & 0.30 & - \\
\hline
\end{tabular}

Note. ${ }^{a}=$ not significant at the $5 \%$ level 
Table 3: Associations between physical occupational exposures and quality of life for men: Results of multivariate linear models ( $\mathrm{N}=8498$ )

\begin{tabular}{|c|c|c|c|c|c|c|}
\hline & \multicolumn{3}{|l|}{ Model 1} & \multicolumn{3}{|l|}{ Model 2} \\
\hline & Coefficient & Standard error & $\mathbf{R}^{2}$ & Coefficient & Standard error & $\mathbf{R}^{2}$ \\
\hline \multicolumn{7}{|l|}{ Ergonomic strain } \\
\hline Retrospective ergonomic strain 2007 & & & 0.026 & & & 0.345 \\
\hline No exposure (reference) & - & & & - & & \\
\hline Moderate exposure & 0.12 & 0.20 & & $0.40 *$ & 0.16 & \\
\hline High exposure & $-0.42 *$ & 0.21 & & $0.40 *$ & 0.17 & \\
\hline Ergonomic strain 1989/1990 & $-0.36 * * *$ & 0.09 & 0.027 & -0.04 & 0.07 & 0.344 \\
\hline \multicolumn{7}{|l|}{ Physical danger } \\
\hline Physical hazards 1989/1990 & $-0.19 * *$ & 0.06 & 0.026 & -0.06 & 0.05 & 0.345 \\
\hline Accident episodes 1978-2009 & & & 0.028 & & & 0.345 \\
\hline No exposure (reference) & - & & & - & & \\
\hline Moderate exposure & $-1.09 * * *$ & 0.25 & & $-0.47 *$ & 0.21 & \\
\hline High exposure & $-1.16 * *$ & 0.37 & & -0.10 & 0.30 & \\
\hline
\end{tabular}




\section{Exposure to harmful chemicals}

Chemical exposures 1956-1998

No exposure (reference)

Moderate exposure

0.03

0.20

0.01

0.16

High exposure

0.02

0.08

0.19

Note. $* \mathrm{p}<0.05 ; * * \mathrm{p}<0.01 ; * * * \mathrm{p}<0.001$

Model 1: Associations between each physical occupational exposure and quality of life, controlled for age, age-squared, occupational grade and ESeC social class.

Model 2: Model $1+$ SF-36 mental and physical component scores. 
Figure 1: Quality of life after labour market exit by physical working conditions among 8498 men in the GAZEL cohort

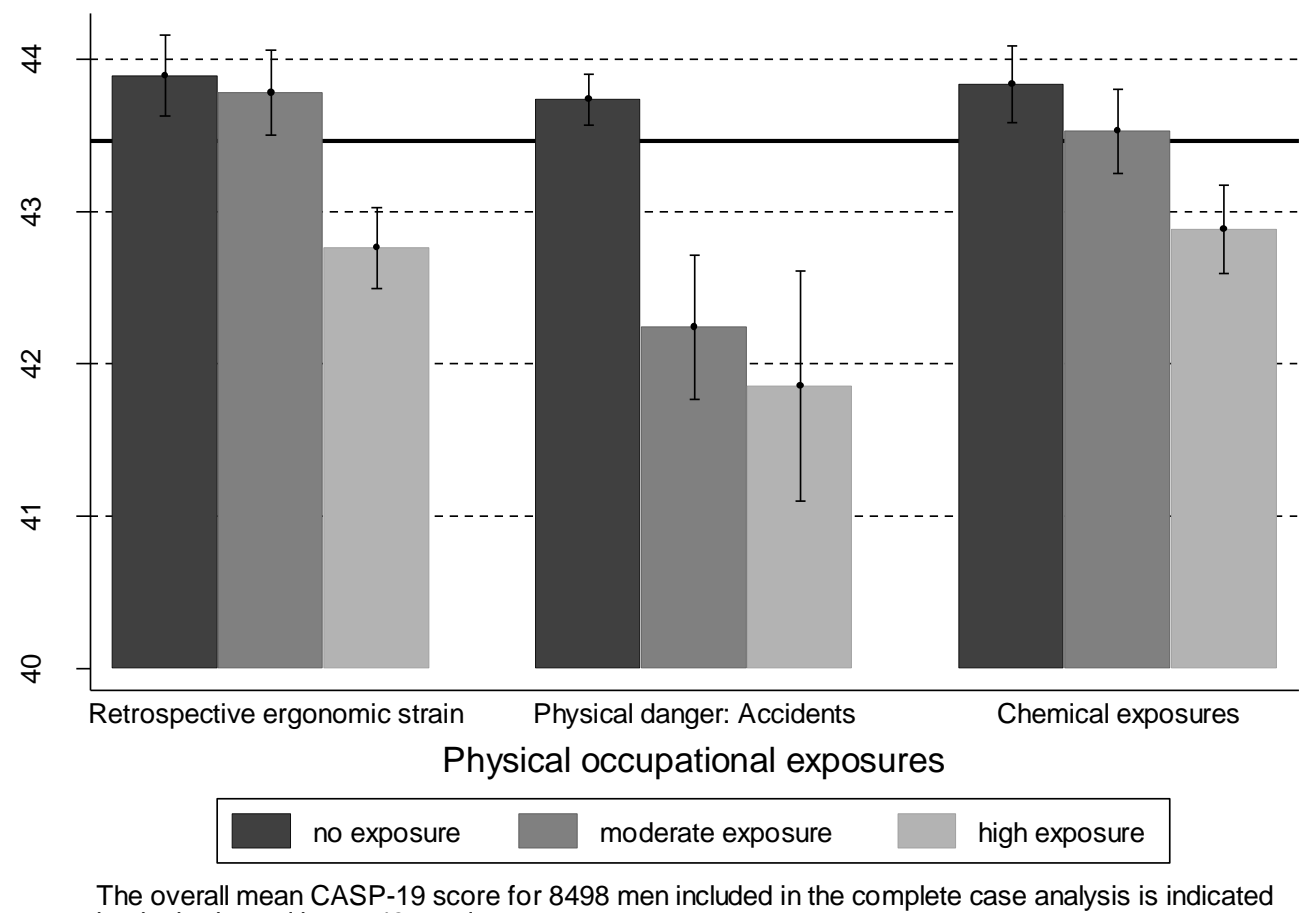

The overall mean CASP-19 score for 8498 men included in the complete case analysis is indicated by the horizontal bar at 43.5 points. 